\title{
Vitamins and Muscular Exercise
}

By G. H. Bourne, London Hospital Medical College, Whitechapel, London, E. I

Vitamins play an important part in the reaction chains concerned with carbohydrate metabolism. Vitamin $B_{1}$, for example, is concerned with decarboxylation and carboxylation of pyruvic acid, one of the intermediary degradation products of carbohydrate breakdown. It also appears to prolong the activity of acetylcholine at nerve endings by the process of inhibition of the formation of cholinesterase which hydrolyses and inactivates acetylcholine. For instance it has been reported that cholinesterase is increased in vitamin $B_{1}$ deficiency (Glick \& Antopol, 1939).

Vitamin $B_{8}$ (pyridoxin) has been found to act in vitro as a hydrogen acceptor and may therefore be concerned in vivo with an oxidation-reduction system.

Pantothenic acid may be concerned with the metabolism of pyruvic acid (Pilgrim, Axelrod \& Elvehjem, 1942). It is of interest in this connexion that Shock \& Sebrell (1944) have shown that if isolated muscle is perfused with a fluid containing calcium pantothenate it is capable of increased work. It has been shown too (Pilgrim et al. 1942) that in the livers of rats suffering from biotin deficiency there was a decreased rate of pyruvate oxidation.

Riboflavin and nicotinic acid both form parts of the complex enzyme systems concerned with hydrogen transport in the living cell.

In the vitamin B complex, therefore, there are four factors-aneurin, riboflavin, nicotinic acid and pyridoxin-and possibly a fifth and sixth-pantothenic acid and biotin-which are concerned with some aspect of metabolism and the requirement for which must surely be increased when the metabolism is speeded up as it is in muscular exercise.

It has been stated (Bicknell \& Prescott, 1945) that the vitamin $B_{1}$ requirement of an individual may be increased fifteen times in severe exercise. This means that, if the daily requirement of $1.5 \mathrm{mg}$./day of a sedentary man weighing $70 \mathrm{~kg}$. (U.S.A. National Research Council, 1945), is increased by this amount, the requirement in severe exercise will be $22.5 \mathrm{mg}$.

To obtain this amount one would need to consume:

$6.5 \mathrm{~kg}$. of National Wheatmeal bread, $75^{\circ} \mathrm{g}$. of commercial wheat germ,

$90 \mathrm{~g}$. of dried brewer's yeast, $12.5 \mathrm{~kg}$. of lean meat.

Even if the daily requirement were increased only four or five times (a more likely figure for most athletes in training) this increase would still require a very considerable intake of natural foods before it could be satisfied. One should consider therefore whether an athlete attempting to attain Olympic standard can fulfil his increased vitamin requirement from the foods he normally eats. Is, in fact, his performance limited by his vitamin intake which is itself limited by the amount of food he can eat?

If the requirement for vitamin $B_{1}$ is so greatly increased in severe muscular exercise, it is highly probable that other members of the vitamin B complex, such as riboflavin and nicotinic acid, may also be needed in similarly increased amounts. We know that 
athletes will, if they can, consume astonishing amounts of animal-protein foods during training - meat, liver, eggs and so on. There seems to be some evidence that they benefit by so doing. I would suggest, however, that the benefit obtained may be due not to the protein but to vitamins such as riboflavin and nicotinic acid which are contained in these foods. That large amounts of animal proteins are not essential is shown by the fact that some Olympic champions, e.g. Nurmi of Finland, are vegetarians.

Since it has been suggested that it is difficult to obtain enough of the members of the vitamin $B$ complex from the food normally eaten one should expect good results from supplementation of the athletes' diets with extra vitamins. In this respect we must remember that large doses of some vitamins may have super-physiological or pharmacodynamical action.

Inspection of the literature shows no conformity of results. Gounelle (1940) said that supplementation of the diets of cyclists with vitamin $B_{1}$ improved their performance. McCormick (1940) obtained a similar result for swimmers, but Karpovich \& Millman (1942) obtained contrary results. Simonson, Enzer, Baer \& Braun (1942) found that supplements of aneurin, nicotinamide and riboflavin did not improve the performance in simple muscular work but delayed the onset of fatigue in neuromuscular work, a result in accordance with that of Hills (1942), who found that extra vitamin $B_{1}$ reduced proneness to accidents in a group of workers.

Keys \& Henschel (1942) found that mixed vitamins in addition to normal army rations did not retard the development of, or hasten the recovery from, fatigue, but Harper, Mackay, Raper \& Camm (1943) found in a series of carefully controlled experiments that mixed vitamin supplementation increased the vital capacity of a group of students.

I have found (Bourne, 1943) that rats injected with aneurin or aneurin ascorbate ran longer in a treadmill before becoming fatigued than untreated rats. Although this difference existed it was not of high statistical significance though, had the experiments been continued with more animals, it might have proved so.

The results of the supplementation of a normal diet in severe exercise are, therefore, still equivocal. Theoretically there should be an increased demand, but the difficulties of human experimentation make this difficult to prove.

Large doses of vitamin $\mathrm{C}$ are said to have a beneficial effect in muscular exercise (Rugg-Gunn, 1938; Sobecki, 1939; Brunner, 1941), though Jetzler \& Haffter (1939) found no such effect.

There is no evidence that vitamin $\mathrm{C}$ is concerned with the carbohydrate cycle, but Giroud \& Ratsimamanga (1939) state that it is concerned with the elimination of lactic acid after exercise.

\section{Conclusion}

On the whole, opinion in the literature seems to favour the view that added vitamins have a beneficial effect on muscular exercise. We know that any serious deficiency certainly affects the output of muscular work. Whether the vitamins added in excess satisfy a demand increased by the muscular exercise or whether their action has some pharmaco-dynamical explanation we do not know, but one thing seems certain and 
that is that too little attention has been paid to the vitamin intake of athletes and that in fact the feeding of athletes, with its obsession with calories and proteins, is still in a stage from which the science of nutrition began to emerge half a century ago.

\title{
REFERENCES
}

Bicknell, F. \& Prescott, F. (1945). The Vitamins in Medicine. London: Heinemann.

Bourne, G. H. (r943). Unpublished work.

Brunner, H. (194I). Schweiz. med. Wschr. 7r, 715.

Giroud, A. \& Ratsimamanga, A. R. (1939). Arch. Hosp. p. 891.

Glick, D. \& Antopol, W. (1939). F. Pharmacol. 65, 389.

Gounelle, H. (1940). Bull. Soc. méd. Hop. Paris, 56, 225.

Harper, A. A., Mackay, I. F. S., Raper, H. S. \& Camm, G. L. (1943). Brit. med. F. i, 243.

Hills, H. W. (1942). Brit. med. F. ii, 587.

Jetzler, A. \& Haffter, C. (r939). Wien. med. Wschr. 89, 332.

Karpovich, V. \& Millman, N. (1942). New Engl. med. $\mathscr{Y} .226,88$.

Keys, A. \& Henschel, A. F. (I 942). F. Nutrit. 23, 259.

McCormick, W. J. (1940). Med. Rec. 152, 439.

Pilgrim, F. J., Axelrod, A. E. \& Elvehjem, C. A. (1942). F. biol. Chem. 145, 237.

Rugg-Gunn, M. A. (1938). Y. R. nav. med. Serv. 3, 199.

Shock, N. W. \& Sebrell, W. H. (1944). Amer. F. Physiol. x42, 265.

Simonson, E., Enzer, N., Baer, A. \& Braun, R. (1942). F. industr. Hyg. 24, 83.

Sobecki, G. (1939). Med. Prakt. 13, 299.

U.S.A. National Research Council (1945). Repr. nat. Res. Coun., Wash., no. I22.

\section{Choice of Aircrew}

\author{
By C. A. Rumball (Senior Medical Specialist, Royal Air Force) \\ No. 1, C.M.E., R.A.F., Kelvin House, Cleveland Street, London, W.C. I
}

The essential search in the choice of aircrew is to find men who are physically fit for flying duties in any part of the world. They must also possess a stable temperament, and a considerable degree of physical and mental stamina, capable of giving many years of trouble-free service in flying. Finally, they must be psychologically fit with a clear aptitude for the particular branch of aircrew duties in which they are to be trained.

It follows from these considerations that a selection board must know as much as possible about the candidate before making a choice. The aircrew examination is designed to present the board with a composite picture of the candidate's mental and physical make-up, and to predict his suitability for particular aircrew duties. The principles governing examination and selection must be capable of application to large numbers, and must be simple, uniform and objective, and must not require complicated apparatus, except for special investigations such as fitness for high-altitude flying.

The cost of training a pilot is considerable. A direct entrant costs $\oint_{1} 16, \infty 00$ to reach operational standard, and to complete operational training on heavy bomber aircraft raises the cost to $£ 20,000$ (Air Ministry, 1948). By reason of cost, every endeavour is made to avoid selection of faulty candidates which would lead to wasteful training. 